\title{
Numerical Methods for the Design and Analysis of Photonic Crystal Fibres
}

\author{
Roberts, John
}

Published in:

IEEE/LEOS Winter Topicals Meeting Series

Link to article, DOI:

10.1109/LEOSWT.2008.4444452

Publication date:

2008

Document Version

Publisher's PDF, also known as Version of record

Link back to DTU Orbit

Citation (APA):

Roberts, J. (2008). Numerical Methods for the Design and Analysis of Photonic Crystal Fibres. In IEEE/LEOS Winter Topicals Meeting Series (pp. MD3.4). IEEE. https://doi.org/10.1109/LEOSWT.2008.4444452

\section{General rights}

Copyright and moral rights for the publications made accessible in the public portal are retained by the authors and/or other copyright owners and it is a condition of accessing publications that users recognise and abide by the legal requirements associated with these rights.

- Users may download and print one copy of any publication from the public portal for the purpose of private study or research.

- You may not further distribute the material or use it for any profit-making activity or commercial gain

- You may freely distribute the URL identifying the publication in the public portal

If you believe that this document breaches copyright please contact us providing details, and we will remove access to the work immediately and investigate your claim. 


\title{
Numerical Methods for the Design and Analysis of Photonic Crystal Fibres
}

\author{
P. J. Roberts \\ Department of Communications, Optics and Materials, Danish Technical University, \\ DK-2800 Kgs. Lyngby, Denmark
}

\begin{abstract}
The numerical methods available for calculating the electromagnetic mode properties of photonic crystal fibres are reviewed. The preferred schemes for analyzing TIR guiding and band gap guiding fibres are contrasted.
\end{abstract}

\section{Summary}

Our current understanding of the properties of photonic crystal fibre (PCF) has come from a combination of experimental and theatrical investigations. Early consideration of the possible guidance within a core surrounded by a regular arrangement of holes in glass concentrated on a photonic band gap mechanism ${ }^{1}$. A short time after this initial numerical study, fibers with a solid silica core and a cladding not predicted to show robust band gaps were fabricated and found by measurement to guide in a single spatial mode essentially over all wavelengths at which silica is transparent ${ }^{2}$. A theoretical understanding of this form of guidance was then established by means of an approximate effective index theory ${ }^{3}$. It was by then understood that two guidance mechanisms can operate in the PCF geometry, one based on the photonic band gap which can enable guiding within a low index core, and the other due to a modified form of total internal reflection (TIR) which requires the core to have a higher refractive index than a suitable averaged index in the cladding.

Although many of the properties of the TIR form of PCF can be calculated to sufficient accuracy by employing the effective index model, a fully quantitative analysis necessarily involves a numerical solution of the underlying Maxwell equations. Accurate results for TIR-PCF can nowadays be obtained with a variety of fast-running mode solvers. The solutions are generally quick to converge since the field variation within the fiber cross section is relatively slowly varying within the glass regions and evanescent within the air holes. The preferred numerical approach depends on the experience of the investigator, whether material dispersion and/or loss are important factors, and also whether confinement loss needs to be calculated. For circular holes, the multipole method ${ }^{4}$ is almost always the most efficient method, particularly if material dispersion and/or confinement loss is relevant. The method owes its efficiency to an analytic description of the Mie scattering from each cylindrical hole.

The calculation of the mode properties of band gap fibers provides more of a numerical challenge than the TIR form since generally the field varies more rapidly, both in amplitude and phase, particularly within the higher index constituents. All-solid band gap (AS-BG) fibre forms, which involve arrangements of higher index inclusions typically within a glass background, are generally relatively easy to deal with since the field variations are not too severe and the geometry does not involve features which are of very different spatial scales. The same numerical methods which are applied to TIR forms will typically also work for AS-BG fibres. The situation is different for hollow core band gap fibres due to the increased index contrast and the thin singly-connected arrangement of glass that forms the microstructure. Typically the thickness of the glass is just 3\% of the cladding pitch and 10\% of the wavelength. Any basis expansion method needs to resolve the associated multi-scale field variations and adequately account for the field boundary conditions at the interfaces. For realistic fibers, typically at least 100,000 basis states need to be incorporated, which significantly limits the choice of numerical scheme. Those that remain appropriate are either based on a plane wave expansion which takes advantage of the speed of the Fast Fourier Transform in an iterative implementation, or on spatial localized basis functions which render the system of equations sparse. The latter form stems most simply from a direct finite-difference (FD) spatial discretization of the underlying wave equation, but better accuracy is obtained from adoption of a finite element (FE) basis. The required solution to the sparse system can be converged by means of a Krylov subspace projection scheme, 
such as the one initiated by Arnoldi, in conjunction with an iterative approach to the calculation of a required matrix inverse within the subspace. This formulation is not dependent on the underlying wave equation being self-adjoint, thus enabling material absorption to be incorporated and the leakage loss to be directly calculated. This aspect also allows for the modes to be found at fixed frequency, rather than at fixed longitudinal wavevector component, which is generally preferred in practical calculations and often essential when material dispersion is relevant. The Arnoldi-based scheme can also be implemented for a plane wave (PW) basis set ${ }^{5}$, but leakage loss can not be extracted due to the enforced periodicity. Such a PW scheme can compete for speed with a variational approach ${ }^{6}$ to mode solving, but has the advantage of being capable of finding modes at a fixed frequency.

There are now several robust FE solvers commercially available ${ }^{7}$. These all adopt some form of Krylov subspace projection and sophisticated pre-conditioning to enable upwards of 100,000 finite elements to be incorporated with fast run-speed. These codes are appropriate for finding the linear mode properties of all types of PCF. It is likely to be very difficult for a small university team to improve upon them without spending many man-years in code development. The availability of such codes enables the researcher to concentrate on other aspects of the electromagnetic propagation within PCF. For example, the field which results from emitters or scatterers within the fibre cross section is not concisely described by a mode expansion. Most commercial codes do not directly deliver the electromagnetic propagator (or Green's function) which is more appropriate in such calculations. The propagator is also useful for exploring quantum optical phenomena within a hollow-core fiber filled with an appropriate gas. Mode properties, such as the group velocity dispersion and nonlinear effective area, are the basic ingredients within nonlinear propagation models based on nonlinear Schrödinger equation (NLSE) forms. The tailorability of these basic mode quantities, which comes from the diversity of PCF geometries and guidance mechanisms, can be explored using a linear mode solver. In conjunction with the NLSE, this continues to lead to the discovery of new regimes of nonlinear propagation.

The analysis of broad-band air-core guiding fibres, such as those which employ a Kagome cladding structure $^{8}$, present a more severe challenge to mode solving than the band-gap form. This is both due to the larger transverse structure that needs to be simulated, and also because there is no complete cladding bandgap so that many modes are close by in effective index to the core-guided mode of interest. Accurate modelling of such fibres, using for example an optimized FE mode-solver, should lead to improved designs and also provide a comparison-test to simple intuitive models that can be used to gain a better understanding for how these fibres guide.

\section{References}

1. T. A. Birks, P. J. Roberts, P. St.J. Russell, D. M. Atkin, T. J. Shepherd, Electron. Lett. 31, 1941 (1995).

2. T. A. Birks, J. C. Knight, and P. S. J. Russell, Opt. Lett. 22, 961-963 (1997)

3. J.C. Knight, T.A. Birks, P.S.J. Russell \& J.P. de Sandro, J. Opt. Soc. Am. A-Opt. Image Sci. Vis. 15, 748-752 (1998)

4. T. P. White, B. T. Kuhlmey, R. C. McPhedran, D. Maystre, G. Renversez, C. M. de Sterke and L. C. Botten, J. Opt. Soc. Am. B 19, 2322-2330 (2002)

5. $\quad$ G.J. Pearce, T.D. Hedley \& D.M. Bird, Phys. Rev. B 71, 195108 (2005)

6. S. G. Johnson and J. D Joannopoulos, Opt. Express 8, 173-190 (2001)

7. JCMwave $\mathrm{GmbH}$, www.jcmwave.com

8. F. Couny, F. Benabid and P. S. Light, Opt. Lett. 31, 3574-3576 (2006) 